\title{
NUEVA ESPAÑA, EL ÚLTIMO BASTIÓN DEL COMERCIO IMPERIAL ESPAÑOL EN EL PROCESO DE APERTURA DE LA CARRERA DE INDIAS (1815-1825)
}

\author{
Arnaud Bartolomei \\ Université Côte d'Azur - CMMC \\ arnaud.bartolomei@univ-cotedazur.fr \\ ORCID: 0000-0001-6775-0226
}

\begin{abstract}
Tradicionalmente, la historiografía sobre la Carrera de Indias ha considerado, en términos generales, que la proclamación del decreto que autorizaba el comercio de Neutrales en noviembre de 1797 provocó la quiebra del sistema monopólico español. Esta hipótesis se basa, sin embargo, en un corpus documental incompleto y en los casos singulares de territorios coloniales que se abrieron muy pronto al comercio de todos los países europeos. El ejemplo del Virreinato de la Nueva España, que aqui estudiamos sobre la base de una amplia revisión de la literatura existente y la contribución de fuentes inéditas, revela otra realidad. El monopolio comercial español resistió a lo largo de las crisis de la época y sólo se acabó desmantelando tras la proclamación de la independencia de México.
\end{abstract}

Palabras clave: Comercio atlántico, Carrera de Indias, monopolio, Nueva España, Cádiz.

\section{THE VICE-ROYALTY OF NEW-SPAIN, THE LAST FoRTRESS OF SPANISH IMPERIAL COMMERCE IN THE BREAK-UP OF CARRERA DE INDIAS (1815-1825)}

The historiography of the Carrera de Indias has generally considered that the proclamation of the decree authorising the trade of Neutrals, in November 1797, caused the bankruptcy of the Spanish monopoly system. This bypothesis is, however, based on incomplete documentary corpus and the singular cases of colonial territories that were opened up very early to the navigation and international trade. The example of New Spain, which we are studying here on the basis of a broad review of existing literature and the contribution of unpublished sources, reveals another reality. The Spanish trade monopoly resisted throughout the 
crises of the revolutionary and Napoleonic period and was finally dismantled only after the proclamation of Mexican independence.

KEYWORDS: Atlantic trade, Carrera de Indias, monopoly, New-Spain, Cadiz.

\section{Introducción}

El período llamado del Libre Comercio ha sido probablemente una de las etapas más estudiadas en la historia de la Carrera de Indias. Una fase caracterizada por la puesta en marcha de diversas medidas que se adoptaron con el objeto de aliviar el cuadro monopolístico que hasta entonces había reservado lo más esencial del comercio español con América a un solo puerto (Sevilla primero y Cádiz después). La primera de aquellas medidas, materializada en los decretos de 1765, consistió en la apertura de diez puertos peninsulares al comercio antillano. Una medida que enseguida fue amplificada por los decretos de 1778 y 1789, los cuales permitieron abrir progresivamente el resto del imperio al conjunto de puertos de la España peninsular (de entrada el Perú, Colombia y el Río de la Plata, en 1778, y después, en 1789, Nueva España y Venezuela), se adoptaron también nuevas tarifas aduaneras (en 1778) y se liberalizaron tanto el comercio intraamericano como la trata negrera. Aquel período ha dado lugar a interpretaciones históricas muy diversas: algunos historiadores, en la estela de John Fisher, han asociado dichas medidas con un crecimiento excepcional de los intercambios marítimos y de la producción manufacturera española (especialmente catalana) y en él han encontrado, además, el símbolo exitoso de las reformas borbónicas y del despotismo ilustrado español. ${ }^{1}$ Otros historiadores, por el contrario, siguiendo las quejas repetidas por los comerciantes de los consulados de Cádiz, México y Lima, han denunciado el falso carácter de un crecimiento comercial que rápidamente habría llevado a una congestión de los mercados coloniales, y han afirmado además que dichas medidas tuvieron un impacto muy pequeño en la producción manufacturera española y que acabarían provocando una cadena de quiebras entre los principales actores de la Carrera de Indias. ${ }^{2}$ Si los debates historiográficos relativos al primer periodo del libre comercio (1765-1796) fueron numerosos y controvertidos, un consenso ha dominado rápidamente el análisis de las tres décadas siguientes (1796-1824), la percepción de las cuales ha evolucionado poco a partir de los estudios pioneros que les de-

1. Fisher, John R., Commercial Relations between Spanish and Spanish America in the Era of Free Trade, 1778-1796, Liverpool, The University of Liverpool, 1985.

2. A propósito de la revisión de las cifras del comercio libre, ver García-Baquero, Antonio, «Los resultados del libre comercio y «el punto de vista»: una revisión desde la estadística», Manuscrits, n. ${ }^{\circ}$ 15, Barcelona, 1997, pp. 303-322. Sobre la opinión de los cargadores de Cádiz relativa a las reformas del comercio libre, ver García-Baquero, Antonio, El libre comercio a examen gaditano. Crítica y opinión en el Cádiz mercantil de fines del siglo XVIII, Cádiz, Universidad de Cádiz 1998. Fundamentalmente, los debates historiográficos sobre el asunto están compilados en Bernal, Antonio Miguel (comp.), El comercio libre entre España y América: 17651824, Madrid, Fundación Banco Exterior, 1987. 
dicó Antonio García-Baquero a finales de los años 1970. ${ }^{3}$ Él fue, en efecto, el primero en proporcionar una descripción cuantitativa de la «crisis» que conoció entonces la Carrera de Indias y en proponer una interpretación global del período. Según su esquema interpretativo, el colapso de la Carrera se habría producido en cuatro tiempos: En primer lugar, la ruptura con Inglaterra, en 1796, y las derrotas navales de 1797 habrían provocado la interrupción de los intercambios marítimos entre España y sus colonias. Esta interrupción habría golpeado las economías americanas, entonces florecientes, y habría afectado sobre todo a aquellas colonias que exportaban productos perecederos (cueros argentinos, azúcar cubano, cacao venezolano), lo que habría obligado a la Corona a suavizar el monopolio de la Carrera de Indias autorizando el comercio con los países neutrales (en noviembre de 1797). La libertad acordada por el decreto de Neutrales habría contribuido a destruir el comercio colonial español, al revelar su naturaleza estrictamente «comisionista», mientras que habría dinamizado, por otro lado, las economías coloniales al abrirles nuevos mercados y nuevas perspectivas de beneficios. Todo ello explicaría finalmente las razones por las cuales las élites comerciales criollas de aquellos territorios habrían rechazado el retorno al orden monopolístico cuando las alianzas de 1808 se dieron completamente la vuelta, y habrían precipitado el final del imperio, a partir del proceso independentista. Un proceso que, tras la derrota de Ayacucho, en 1824, llevó a la desaparición de la presencia imperial española en el continente americano. Tal y como remarcó Pierre Chaunu en un célebre artículo, contrariamente a lo que sucedió con las Trece Colonias británicas, fue la quiebra del monopolio comercial español, y no su refuerzo, lo que habría provocado las independencias en la América hispana. ${ }^{4}$

Desde el punto de vista económico, esta visión de las cosas se basa, por tanto, en la premisa de que el comercio colonial español dependía exclusivamente del monopolio que lo protegía y que no era competitivo en relación con las alternativas que ofrecían los competidores europeos (y estadounidenses). Un planteamiento que ha sido hasta hace poco la idea dominante en los análisis sobre la Carrera de Indias y sobre el sistema imperial español. ${ }^{5}$ En los últimos veinte años, no obstante, varios autores han propuesto una lectura menos unívoca de dichos procesos. Así, mi propia tesis doctoral, defendida en 2007, y aún más el libro que escribí en 2017, planteaba abiertamente la cuestión del sentido que debía darse a las vigorosas reanudaciones del comercio colonial registradas en Cádiz en 1803-1804 y 1808-1810, que ya eran bien conocidas, así como también a las

3. García-Baquero, Antonio, Comercio colonial y guerras revolucionarias. La decadencia económica de Cádiz a raíz de la emancipación americana, Sevilla, Publicaciones de la Escuela de Estudios Hispano-Americanos de Sevilla, 1972.

4. Chaunu, Pierre, «Interprétation de l'indépendance de l'Amérique latine», Bulletin de la Faculté de Lettres de Strasbourg, n. ${ }^{\circ}$, Strasbourg, 1963, pp. 403-421.

5. Está validada, por ejemplo, en grandes líneas por las dos últimas obras magistrales dedicadas al imperio español y a la Carrera de Indias: Bernal, Antonio Miguel, España, proyecto inacabado, Los costes-beneficios del imperio, Madrid, Centro de Estudios Hispánicos e Iberoamericanos, Marcial Pons Historia, 2005 y Delgado Ribas, José María, Dinámicas imperiales (1650-1796): España, América y Europa en el cambio institucional del sistema colonial español, Barcelona, Edicions Bellaterra, 2007. 
—mucho menos documentadas - reanudaciones acaecidas en 1815 y 1820: ¿Cómo se explica que decenas de barcos, cargados con varios millones de pesos de mercancías europeas, eligieran todavía, en aquellas tardías fechas, el puerto de Cádiz para llegar a América, a pesar de que el monopolio español no era vinculante desde hace unos veinte años?. 6 Basándose en fuentes similares o complementarias, y en el contexto de una investigación completamente independiente a la mía, Marina Alfonso Mola ha llegado a algunas conclusiones cuantitativamente convergentes con mis propios análisis y ha puesto de relieve ciertas realidades que permiten comprender mejor la resistencia del comercio colonial en Cádiz en esa época (como el mantenimiento del marco reglamentario del comercio libre hasta 1828 o la vinculación de algunos de los llamados comerciantes criollos al monopolio). ${ }^{7}$ Otros trabajos dedicados al corsarismo insurgente, a las empresas marítimas gaditanas o a la «comisión de reemplazo» encargada de financiar la lucha militar leal, también han contribuido a afinar nuestra comprensión de la época. ${ }^{8}$ Cierta historiografía hispanoamericana ha puesto de relieve, por su parte, algunas realidades comerciales americanas que no coincidían con el discurso que equiparaba la época con una crisis general del sistema de monopolio de la Carrera de Indias, realidades como el dinamismo de los recién creados consulados en Veracruz y Guadalajara, o el éxito de ciertas empresas mercantiles mexicanas o peruanas. ${ }^{9}$ Por el contrario, todas estas obras convergen en torno a la idea de que en los baluartes del sistema imperial español (Cádiz, Nueva España y Perú), el monopolio habría resistido a la crisis de la Carrera de Indias hasta principios de la década de 1820 .

Estos son los diferentes elementos del conocimiento histórico reciente que voy a confrontar con mi propio y reciente trabajo de archivo, con el objeto de elaborar un nuevo

6. Bartolomei, Arnaud, Les marchands français de Cadix et la crise de la Carrera de Indias (1778-1828), Madrid, Casa de Velázquez, 2017.

7. Alfonso Mola, Marina, «1828. El fin del libre comercio», en Martínez Shaw, José María Carlos; Oliva Melgar (comps.), El sistema atlántico español (siglos XVII-XIX), Madrid, Marcial Pons, 2005, pp. 311-349, y «El tráfico marítimo de la Carrera de Indias en las agitadas aguas de las independencias», en Silva, Hernán Asdrúbal (comp.), Historia económica del cono sur de América. Argentina, Bolivia, Brasil, Chile, Paraguay y Uruguay. La era de las revoluciones y la independencia, México, Instituto Panamericano de Geografía e Historia, 2010, pp. 93-179. Sobre la cuestión del tropismo de los mercaderes criollos en favor del monopolio, ver también la tesis doctoral de Mariano Martín Schlez, Los circuitos comerciales tardo-coloniales: El caso de un comerciante monopolista: Diego de Agüero (1770-1820), Buenos Aires, Universidad de Buenos Aires, 2014.

8. Gámez Duarte, Feliciano, Luchar contra el mar, edificar en el viento. La Compañía gaditana Viniegra, 1797-1829, Cádiz, Ayuntamiento de Cádiz, 1999 y Del uno al otro confín. España y la lucha contra el corso insurgente hispanoamericano, Cádiz, Diputación de Cádiz,, 2008. Malamud, Carlos, «Sin marina, sin tesoro y casi sin soldados». La financiación de la reconquista de América, 1810-1826, Santiago, Centro de Estudios Bicentenario, 2007.

9. Souto Mantecón, Matilde, Mar abierto. La política y el comercio del Consulado de Veracruz en el ocaso del sistema imperial, México, El Colegio de México, Centro de Estudios Históricos, Instituto José María Luis Mora, 2001. Ibarra, Antonio, Mercado e institución: corporaciones comerciales, redes de negocios y crisis colonial. Guadalajara en el siglo XVIII, México, Universidad Autónoma de México, Bonilla Artigas Editores, 2017. Mazzeo, Cristina, El comercio libre en el Perú. Las estrategias de un comerciante criollo: José Antonio de Lavalle y Cortés, 1777-1815, Lima, Pontificia Universidad Católica del Perú, Fondo Editorial, 1994. 
cuadro y una nueva interpretación de la forma en que tuvieron lugar, entre 1815 y 1825 , los procesos de la desaparición de la Carrera de Indias así como la apertura de los mercados hispanoamericanos a todos los países europeos. Para ello, he elegido estudiar una de las rutas comerciales más emblemáticas de la Carrera de Indias (la ruta comercial de la Nueva España), y los dos puertos que, durante casi tres siglos, fueron los principales centros de ese comercio: Cádiz, por un lado, y Veracruz, por el otro. Lo que ocurrió en dichos dos puertos es probablemente muy diferente de lo que ocurrió en Buenos Aires, Caracas o La Habana, pero creo que es importante conocerlo para llegar a una lectura más compleja y menos lineal de los procesos estudiados. Después de presentar las diferentes fuentes que me han permitido reconstruir la evolución cuantitativa del comercio colonial en Nueva España durante aquella década, concluiré esbozando algunas posibles explicaciones de la resistencia de este reducto del comercio imperial así como los cambios que esta contribución induce en nuestra percepción de la crisis de la Carrera de Indias.

\section{Nuevas fuentes para un viejo debate}

La principal dificultad para el estudio del comercio exterior mexicano durante el último decenio de la Carrera de Indias es el carácter heterogéneo, impreciso e incompleto de las fuentes publicadas hasta el momento. Las dos principales series realizadas sobre el comercio colonial español de la época (la de García-Baquero, en 1972, y la de Fisher, en 1993 ) tienen dos limitaciones que no cuestionan, sin embargo, su importancia ni ponen en duda la exactitud de los estudios realizados por los dos historiadores. Por un lado, ambas series se basan exclusivamente en los registros del Archivo General de Indias, cuyas colecciones se volvieron cada vez más incompletas, especialmente después de $1810 .{ }^{10}$ Por otra parte, ambas series agregan, en la mayoría de los casos, los resultados de las diferentes provincias americanas, tanto las que se abrieron al comercio exterior en una fase muy temprana (Río de la Plata y Cuba) como las que permanecieron más tiempo en el campo leal y monopólico (Perú, Nueva España). Estos dos sesgos contribuyeron en gran medida a alimentar la idea de que el comercio colonial español había disminuido fuertemente después de las reanudaciones esporádicas de la Paz de Amiens y de 1808-1810, y, por lo tanto, anclaron la tesis de que el Decreto de los Neutrales de 1797 había sido el acontecimiento decisivo en el declive del comercio colonial español. Al mismo tiempo, sin embargo, Javier Ortiz de la Tabla dio una visión significativamente diferente de la situación. Lo hizo basándose no sólo en los registros del Archivo General de Indias sino también en otras fuentes complementarias para cotejar sus informaciones, como por ejemplo los datos de las balanzas del comercio elaboradas por el Consulado de Veracruz para el periodo 1796-1821 que documentan muy precisamente el valor, la naturaleza y el

10. García-Baquero, Antonio, Comercio colonial..., cit., Fisher, John R., El comercio entre España e Hispanoamérica: 1797-1820, Madrid, Banco de España, 1993. 
origen de las mercancías intercambiadas en el puerto de Veracruz. ${ }^{11}$ Pero, aunque estos últimos datos ilustran de la mejor mañera la resistencia del comercio oficial llevado a cabo en el puerto, por diversas razones, los resultados de su trabajo no lograron influir en el discurso general sobre el comercio colonial español. Por eso, nos proponemos discutirles de nuevo aquí, confrontándoles a otros cuatro corpus de fuentes, alternativas a los registros del Archivo General de Indias: primero, las fuentes mexicanas (en las cuales incluimos las balanzas del Consulado de Veracruz), luego las fuentes gaditanas, en particular la prensa mercantil, también algunos documentos inéditos extraídos de las secciones menos utilizadas «Arribadas» y «Ultramar» del Archivo General de Indias y, por último, las fuentes producidas por cónsules extranjeros.

La comparación de estas diferentes fuentes permite concluir que hasta 1821, e incluso hasta 1822, los puertos españoles (y Cádiz en primer lugar) siguieron siendo nodos esenciales para el comercio entre México y Europa; sin embargo, para 1825 los puertos peninsulares ya habían quedado totalmente marginados y el intenso comercio marítimo mexicano se vinculaba directamente con los puertos europeos no españoles. Según estos resultados, el momento decisivo en el colapso del comercio colonial de Nueva España se produjo, por tanto, entre 1822 y 1824, lo que equivale a un singular reajuste en el análisis clásico de la crisis de la Carrera de Indias: visto desde México, el acontecimiento más importante de la susodicha crisis no fue el decreto de 1797, ni la crisis política de 1808 , sino más bien la declaración de independencia en el otoño de 1821, o incluso la toma del fuerte de San Juan de Ulúa por los mexicanos en 1825. Es esa idea la que quiero defender en este artículo presentando a continuación cada una de las series estadísticas disponibles y las conclusiones que se pueden extraer de su confrontación.

\section{La crisis de la carrera de indias en las fuentes mexicanas}

El término «fuentes mexicanas» se refiere a todas las fuentes producidas por instituciones que en el momento estudiado tenían su sede en México (como los Consulados de la Ciudad de México y de Veracruz, o como el Ayuntamiento y la Aduana de Veracruz, por ejemplo) y cuyos fondos, por lo tanto, se conservan generalmente en los archivos mexicanos y no en el Archivo General de Indias.

Probablemente, una de las series más completas e interesantes de este conjunto es la elaborada por Robert Smith, la cual se publicó en un artículo editado en 1943, aunque ha sido después poco utilizada. ${ }^{12}$ Se trata de una serie basada en los registros conservados en el Archivo Municipal de Veracruz los cuales documentan, de manera relativamente homogénea para el período 1790-1821, la recaudación de un impuesto (el derecho de agua)

11. Ortiz de la Tabla Ducasse, Javier, El comercio exterior de Veracruz, 1778-1821: crisis de dependencia, Sevilla, Escuela de Estudios Hispano-Americanos, 1978.

12. Smith, Roberts S., «Shipping in the Port of Veracruz, 1790-1821», Hispanic American History Review, n. ${ }^{\circ} 23$, Durham, 1943, pp. 5-20. 
que se exigía a todos los buques que entraban en el puerto, excluidos los dedicados al comercio costero y los buques de guerra. Utilizamos estos datos para elaborar dos gráficos: el primero representa el número total de buques que entran en el puerto de Veracruz (véase la Figura 1) y el segundo los desglosa según su país de origen (véase la Figura 2).

Figura 1. Entradas de buques en el puerto de Veracruz entre 1790 y 1821 a partir de los archivos del «derecho de agua» (sin contabilizar embarcaciones de cabotaje ni navíos de guerra).

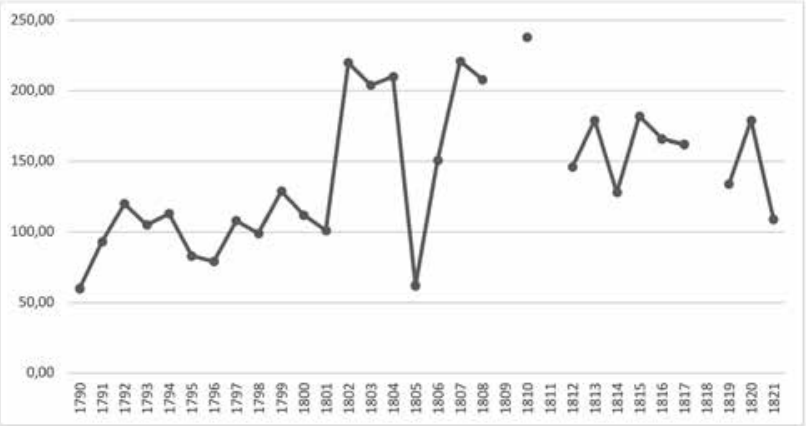

FuENTE: Smith, Roberts S., «Shipping in the Port of Veracruz...», cit., p. 10.

FiguRA 2. Entradas de buques en el puerto de Veracruz entre 1790 y 1821 a partir de los archivos del «derecho de agua», con indicación de su puerto de origen (sin contabilizar embarcaciones de cabotaje ni navíos de guerra).

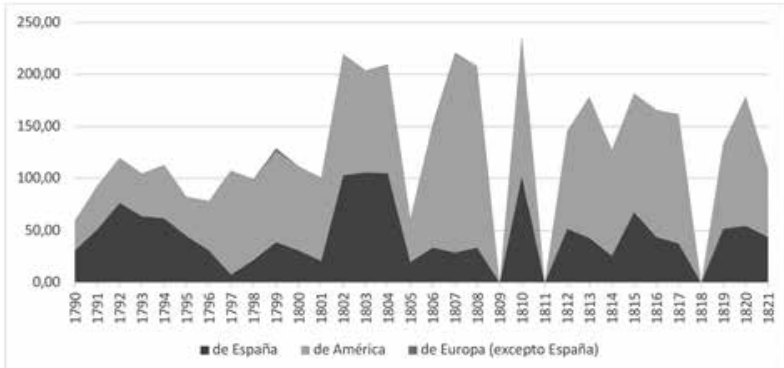

FuENTE: Smith, Roberts S., «Shipping in the Port of Veracruz...», cit., p. 10.

Así pues, este conjunto de datos pone de relieve varios resultados importantes. En primer lugar, pone en perspectiva la idea misma de que hubo una crisis general en la Carrera de Indias. No lo parece cuando miramos el lado mexicano. Hay que admitir que la curva es muy desigual, lo que es un reflejo obvio de la situación bélica del momento. Pero, en general, el número de barcos que entran en el puerto de Veracruz parece mucho mayor durante las dos primeras décadas del siglo XIX (150-200 barcos por año) que durante la última década del siglo XVIII (50-100 barcos por año). Además, los datos sugieren que el dinamismo de la portuaria ciudad de Veracruz se basó principalmente en el trans- 
porte marítimo intraamericano, que representó casi dos tercios de los buques que entraron en su puerto durante el período. Hasta 1821, sin embargo, el número de barcos procedentes de España se mantuvo en un nivel alto, y muy similar al de la década de 1790 (alrededor de 50 por año). El número de embarcaciones que llegaron directamente de los puertos europeos, por otro lado, era infinitesimal (sólo 9 de 4.101). En general, por lo tanto, estos datos demuestran que aunque la navegación entre España y el Virreinato de la Nueva España sufrió la situación bélica de la época (particularmente en 1797-1801 y 1805-1807), recuperó una fuerza innegable después del cambio de rumbo de 1808 (casi siempre más de 40 barcos por año, más que a principios de la década de 1790) y se mantuvo relativamente activa hasta el final del período.

Una segunda serie estadística de entradas en el puerto de Veracruz fue reconstruida y publicada por Mario Trujillo Bolio en 2009. ${ }^{13}$ Agrega datos heterogéneos, a veces de fuentes aduaneras mexicanas, a veces de la prensa mexicana (Gazeta de México, 17981808, Jornal Económico y Mercantil de Veracruz, 1806, Correo Semanario Político y Mercantil de México, 1808-1810) y otras veces de la prensa mercantil gaditana (Vigía, 17981825). Este hecho dificulta la manipulación de las estadísticas producidas, ya que en algunos años los datos documentan la totalidad de las entradas de barcos en el puerto veracruzano (1798-1808) y en otros sólo las entradas de buques procedentes de Cádiz (1808-1825). Aquella serie resulta útil, sin embargo, en dos cuestiones que aparecen particularmente claras en el siguiente gráfico (véase las Figuras 3 y 4).

FIgURA 3. Entradas de buques en el puerto de Veracruz procedentes de Cádiz, o de Cádiz y La Habana (en número de buques), 1796-1825.

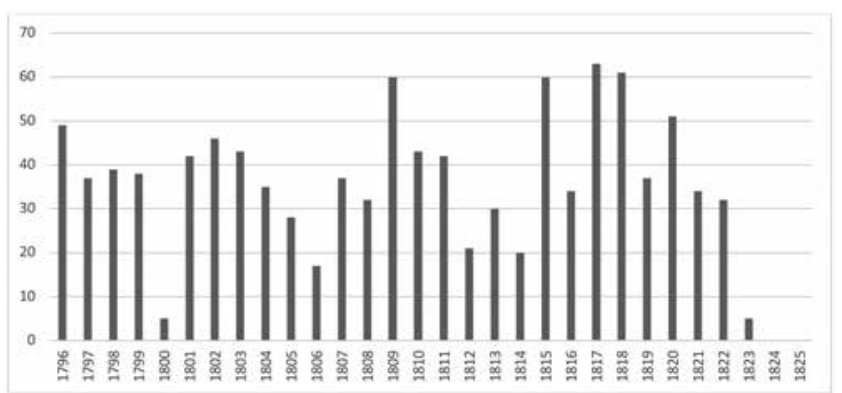

Fuente: Trujillo Bolio, Mario, El Péndulo marítimo-mercantil en el Atlántico novohispano (1798-1825). Comercio libre, circuitos de intercambio, exportación e importación, México-Cádiz, CIESAS, Universidad de Cádiz, 2009, pp. 45-72.

Los datos propuestos por Trujillo confirman, por una parte, que los viajes mercantes entre el virreinato de la Nueva España y Cádiz se mantuvieron con regularidad y resistencia hasta 1822: se aprecia que desde el puerto andaluz se despacharon sistemáticamente

13. Trujillo Bolio, Mario, El Péndulo marítimo-mercantil en el Atlántico novohispano (1798-1825). Comercio libre, circuitos de intercambio, exportación e importación, México, Cádiz, CIESAS, Universidad de Cádiz 2009, pp. 45-72. 
más de 30 barcos anuales con destino Veracruz, con la excepción de sólo cuatro años $(1800,1806,1812$ y 1814). Por otra parte, esa serie permite completar los datos publicados por Robert Smith en un punto que dicha fuente no lo permitía: la importancia relativa de los enlaces marítimos mantenidos con los puertos de los Estados Unidos de forma casi constante y a lo largo del decenio de 1798-1808, período durante el cual se permitió el comercio con países neutrales. Con 78 barcos procedentes de puertos de EE.UU. y sólo 4 de puertos europeos, estas entradas de barcos, concentradas en los años 1798-1800 y 1805-1808, representan, sin embargo, menos del $10 \%$ del total de las 960 entradas de barcos registradas por Mario Trujillo. ${ }^{14}$

FIgURA 4. Buques entrados en el puerto de Veracruz en función de la localización de su puerto de origen (en número de embarcaciones), 1796-1825.

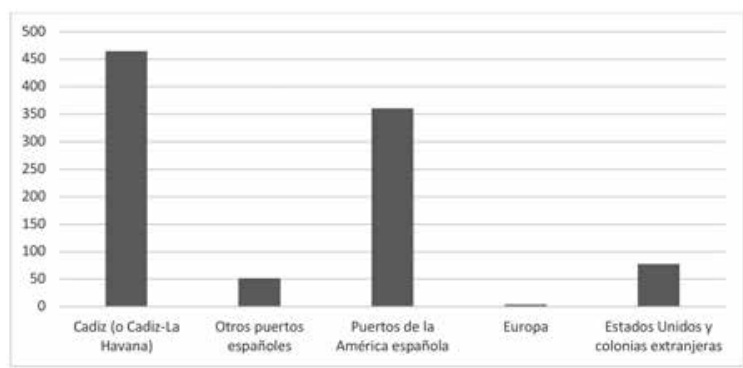

FuENTE: Trujillo Bolio, Mario, El Péndulo marítimo-mercantil..., cit., pp. 45-72.

Se podría destacar que el movimiento marítimo de un puerto sólo da una información parcial sobre su comercio, pues no aporta precisiones sobre el tamaño de esos barcos, el volumen de sus cargamentos y, aun menos, sobre su valor —el cual depende mucho de la naturaleza de las mercancías transportadas-. Pero, los datos sobre el movimiento marítimo del puerto de Veracruz reunidos por estos dos historiadores están ampliamente validados por las series estadísticas producidas a partir de las balanzas co-

14. Javier Ortiz de la Tabla por su parte menciona 160 entradas de navíos neutrales en el puerto de Veracruz para todo el periodo: 56 en 1798 et 1799, 125 en los años 1805-1807 y 27 en 1817 y 1818 (Ortiz de la Tabla, Javier, El comercio exterior de Veracruz, 1778-1821: crisis de dependencia, Sevilla, Escuela de Estudios HispanoAmericanos, 1978, p. 326). Carlos Marichal menciona la llegada de 108 navíos extranjeros entre 1806 y 1808 , 70 armados por la cuenta de las consorcios Hope y Baring (70) y 38 de Gordon y Murphy (Marichal, Carlos «El comercio neutral y los consorcios extranjeros en Veracruz, 1805-1808», en Yuste López, Carmen y Matilde Souto Mantecón (comps.), El comercio exterior de México (1713-1850), México, Instituto de Investigaciones «Dr. José María Luis Mora», Instituto de Investigaciones Históricas, Universidad Veracruzana, 2000, p. 164). Matilde Souto Mantecón adelanta la cifra de 115 entradas de navíos extranjeros: 30 durante los años 1797-1799 y 85 en 1805-1808 (Souto Mantecón, Matilde, Mar abierto. La política y el comercio del Consulado de Veracruz en el ocaso del sistema imperial, El Colegio de México, Centro de Estudios Históricos, Instituto José María Luis Mora, 2001, p. 196, 200 y 208). Las diferencias en las cifras proveen del hecho que una parte de los navíos neutrales también podían provenir de puertos españoles habilitados. Pero, aun considerando las más altas de esas cifras, el número total de barcos sigue siendo mínimo en comparación del movimiento total del puerto durante el periodo considerado. 
merciales publicadas por el Consulado de Veracruz sin discontinuidad entre 1796 y 1821. Estos datos, aunque se conocen desde hace mucho tiempo, adquieren un significado especial cuando se reproducen en forma gráfica. ${ }^{15}$ Confirman el vigor del comercio marítimo en el puerto de Veracruz en la época de la crisis de la Carrera de Indias, un período que incluso puede haber sido el más brillante de su historia (entre 1797 y 1820), según una seria reconstrucción estadística llevada a cabo por el cónsul francés en dicho puerto, en $1856 .{ }^{16}$ Estos datos revelan también, por otro lado, el dominio que los españoles siguieron ejerciendo sobre este comercio a lo largo de aquel período, ya que el $70 \%$ del volumen del comercio exterior de Veracruz se realizaba con los puertos peninsulares, frente a únicamente el $20 \%$ de los puertos «americanos» de las demás colonias españolas y sólo el $10 \%$ de los puertos extranjeros (véanse las Figuras 5 y 6).

FiguRA 5. Valor de las importaciones del puerto de Veracruz según las balanzas de Quirós (en millones de pesos), 1796-1825.

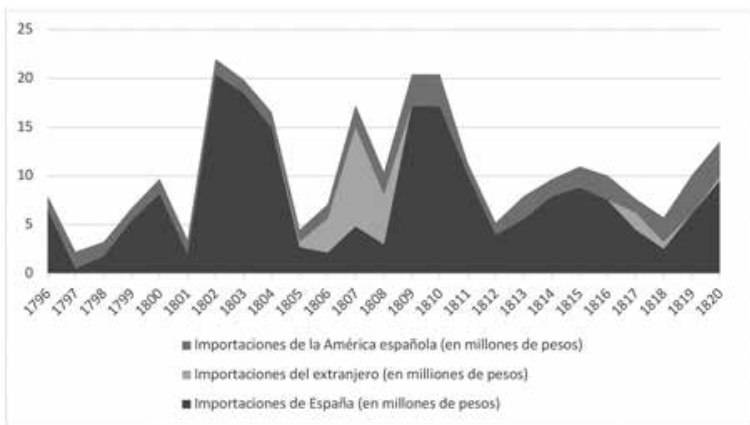

FUENTE: Elaboración propia a partir de ANP, AE, BIII, 452, «Estado o Balanza General de comercio reciproco, hecho por este puerto con los de España y América y algunos estrangeros en los 25 años corridos desde el de 1796, primero después de la erección de este Consulado, hasta el de 1820 inclusive» (José María Quirós, Veracruz, 18 de abril de 1821).

Podemos obviamente preguntarnos sobre el valor de estas cifras y considerar que sólo nos ofrecen una visión parcial de la verdadera apertura comercial de la Nueva España. El contrabando, que debía afectar principalmente a los buques europeos y americanos, no se muestra; y el cuadro sólo recoge la situación en el puerto de Veracruz y no los

15. Por mi parte, utilicé un impreso del cuadro sintético producido por Quirós en 1821. Este documento, conservado en los archivos consulares franceses, contiene datos que ya fueron publicados y comentados varias veces desde el siglo XIX. Archives Nationales de Paris (ANP), Affaires étrangères (AE), BIII, 452, José María Quirós «Estado o Balanza General de comercio reciproco, hecho por este puerto con los de España y América y algunos estrangeros en los 25 años corridos desde el de 1796, primero después de la erección de este Consulado, hasta el de 1820 inclusive», Veracruz, 18 de abril de 1821. Ver Lerdo de Tejada, Miguel, Comercio exterior de México desde la conquista hasta hoy, México, Banco Nacional de Comercio Exterior, 1967, passim, Ortiz de la Tabla Ducasse, Javier, El comercio exterior de Veracruz..., cit., passim.

16. ANP, F12, 2695, 1, «Notes sur la navigation et le commerce du port de Veracruz pendant l'année 1856», 1 de octubre de 1859. Este informe del cónsul francés en el puerto, Jules Doaran, contiene una larga parte introductoria compilando muchos documentos relativos a la historia comercial de Veracruz. 
puertos de la región de Tampico, los cuales fueron más acogedores a los buques extranjeros que el de Veracruz y se abrieron gradualmente, a partir de 1814, al comercio exterior. Hay también que considerar que algunos de los bienes importados desde las otras colonias americanas (de Cuba en primer lugar) habían sido importados indirectamente de Europa o de los Estados Unidos. No obstante, tampoco parecen totalmente erróneos o falsificados, pues los datos de las balanzas proporcionan también un testimonio muy preciso y exacto sobre el famoso comercio que tuvo lugar entre Veracruz y Europa en la época de los contratos que se negociaron entre la Corona y los consorcios Hope-BaringOuvrard y Gordon Murphy (principalmente en 1806-1809). Recordemos, pues, que, en conjunto, estas cifras confirman la impresión sugerida por las del derecho del agua: hasta principios de la década de 1820, el comercio en Veracruz era muy activo y los comerciantes y armadores españoles habían conservado allí una gran importancia.

FiguRA 6. Reparto de las importaciones de Veracruz en función del puerto de origen de las mercancías (1796-1820).

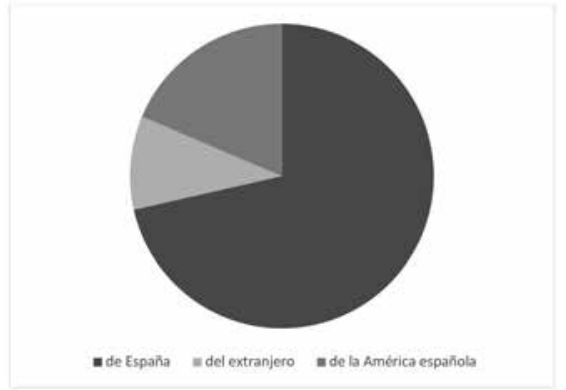

FUENTE: Elaboración propia a partir de ANP, AE, BIII, 452, «Estado o Balanza General de comercio reciproco, hecho por este puerto con los de España y América y algunos estrangeros en los 25 años corridos desde el de 1796, primero después de la erección de este Consulado, hasta el de 1820 inclusive» (José María Quirós, Veracruz, Veracruz, 18 de abril de 1821).

Las primeras balanzas comerciales publicadas por las autoridades republicanas mexicanas a partir de 1825 revelan, sin embargo, que dicha situación había cambiado radical y abruptamente sólo cuatro años después de la declaración de independencia. Para 1825, ninguno de los 458 barcos que entraron en un puerto mexicano venía desde España (o desde alguna colonia española), ni enarbolaba el pabellón español. El caso de Veracruz es muy significativo a este respecto (véanse las Figuras 7 y 8).

Las fuentes mexicanas coinciden, pues, en una cosa: el comercio oficial del puerto de Veracruz siguió siendo una especie de «coto» de mercaderes y armadores españoles hasta 1821, cuando fueron brutalmente desalojados y el puerto se transformó en un emporio internacional, abierto a mercaderes y banderas de todo el mundo (excepto al pabellón español). ${ }^{17}$ Esas fuentes no permiten, sin embargo, comprender qué es exactamente lo

17. La apertura de los puertos mejicanos fue practicada justo después de la declaración de Independencia (al parecer el 9 de noviembre de 1821) y fue sancionada por el gobierno de la Regencia el 15 de diciembre si- 
que ocurrió durante los tres años decisivos de 1822, 1823 y 1824, cuando el control del puerto de Veracruz fue objeto de una feroz lucha entre las autoridades mexicanas, las cuales se habían apoderado de la ciudad, y los restos del ejército español, los cuales quedaron atrincherados en el fuerte de San Juan de Ulúa. ${ }^{18}$ La prensa mercantil, en particular la de Cádiz, conservada en muy buen estado, permite aclarar este último punto, a la vez que permite confirmar el panorama general.

Figura 7. Puertos de origen de los buques entrados en el puerto de Veracruz en 1825.

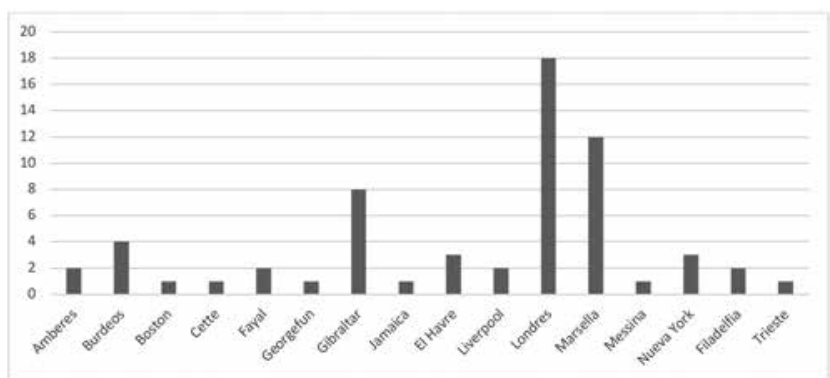

FuENTE: Ildefonso Maniau, Balanza comercial de México para el año 1825, México, Secretaría de Hacienda, 1826.

FIgURA 8. Pabellones de los barcos entrados en el puerto de Veracruz en 1825.

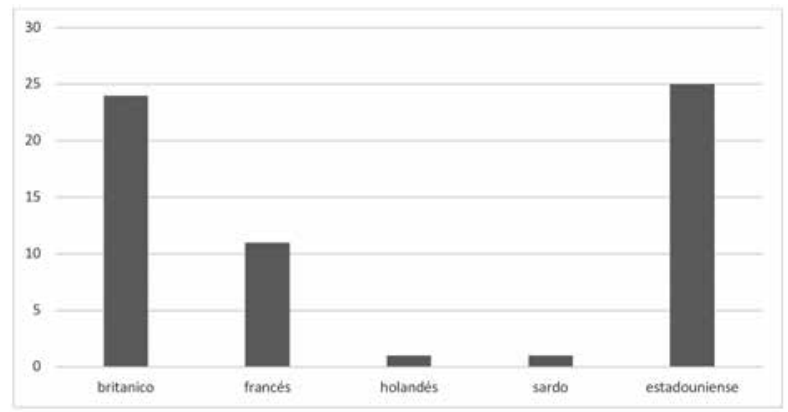

FuENTE: Ildefonso Maniau, Balanza comercial de México..., cit.

\section{El comercio mexicano visto desde el vigía de Cádiz}

Los informes diarios realizados por la guardia portuaria de Cádiz se hacían públicos en una publicación semanal sin título, comúnmente conocida como Parte semanal de la Vi-

guiente. Siguió siendo vigente en las décadas siguientes, excepto para los países que se declararon en estado de guerra con la república (España hasta 1836, Francia en 1838 y 1839 y Estados Unidos entre 1845 y 1848). Ver Lerdo de Tejada, Miguel, Comercio exterior de México desde la conquista..., cit., p. 30.

18. Ortiz Escamilla, Juan, El teatro de la guerra. Veracruz, 1750-1825, Castelló de la Plana, Universitat Jaume I, 2008. 
gía de Cádiz, o el Vigía, la cual resumía el movimiento de los buques que habían entrado y salido de dicho puerto durante la semana anterior y proporcionaba además una lista de los buques presentes en la bahía. El Vigía también publicó anualmente las estadísticas generales del año anterior, mediante las que obtenemos un panorama claro de la evolución de la navegación entre Cádiz y la América hispana durante todo el período considerado. ${ }^{19}$ Los análisis estadísticos que se han extraído del estudio de dichos datos, tanto los publicados por Marina Alfonso Mola como los que aquí propongo, confirman la increíble y poco conocida resistencia que muestra el puerto de Cádiz en el comercio marítimo entre Europa e Hispanoamérica. De hecho, entre 1802 y 1828, más de 5.000 barcos habrían entrado o salido del puerto de Cádiz, procedentes de, o con destino a, la América Hispana, cifra casi dos veces superior a las publicadas anteriormente por John Fisher y Antonio García-Baquero para el período 1797-1821 (2.667 buques). ${ }^{20}$ A la cifra global de 5.019 embarcaciones hay que añadir también los 299 barcos aproximadamente que, según el Vigía, fueron capturados durante este período por corsarios insurgentes a su entrada o salida del puerto de Cádiz. No obstante, dicha resistencia del comercio gaditano no se manifestó durante todo el período considerado de forma homogénea, ni tampoco lo hizo de igual manera con las diferentes provincias americanas implicadas. Un análisis más detallado de esos datos revela que todos los socios americanos sufrieron con la misma violencia las dos profundas interrupciones vinculadas a los períodos en que el bloqueo británico fue más severo (1797-1801 y 1805-1807), si bien las situaciones se diferenciaron después en tres patrones muy diferentes (ver Figuras 9, 10 y 11).

FiguRA 9. Entradas de buques en el puerto de Cádiz procedentes del Río de la Plata (reparto en función de sus pabellones), 1798-1834.

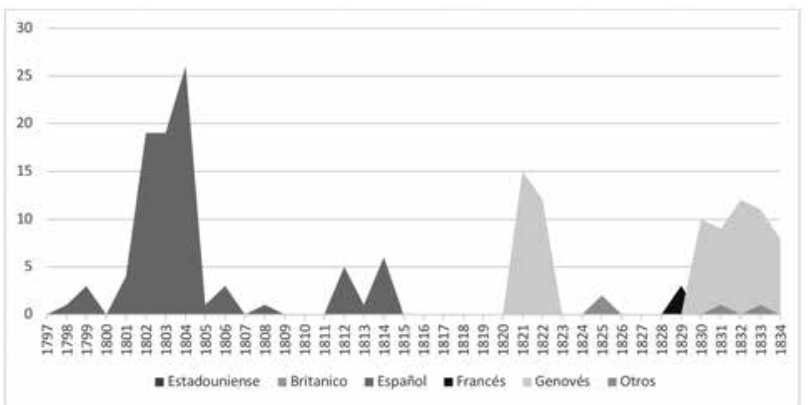

FuENTE: Elaboración propia a partir del Parte semanal de la Vigía de Cádiz, 1798-1808 y 1812-1834 (colección consultada en la Biblioteca de Temas Gaditanos, Cádiz).

19. La colección conservada en la Biblioteca de Temas Gaditanos (BTG) empieza en 1798 y es casi completa para todo el siglo XIX (sólo faltan los números de 1810, 1811 y 1812). También existen colecciones más parciales en otros archivos, como la que se encuentra en los archivos consulares franceses, que contiene 200 ejemplares del periodo 1788-1796, y de la cual he sacado la totalidad de los datos disponibles para el año 1789 (ver Bartolomei, Arnaud, «Cadix et la Méditerranée à la fin du XVIII ${ }^{\mathrm{e}}$ siècle», Revue d'Histoire Maritime, n. ${ }^{\circ} 13$, Paris, 2011, pp. 173-209; <https://halshs.archives-ouvertes.fr/halshs-03156661/document>.

20. Alfonso Mola, Marina, El tráfico marítimo de la Carrera de Indias..., cit., p. 129. 
FiguRA 10. Entradas de buques en el puerto de Cádiz procedentes de las Antillas (reparto en función de sus pabellones), 1798-1834.

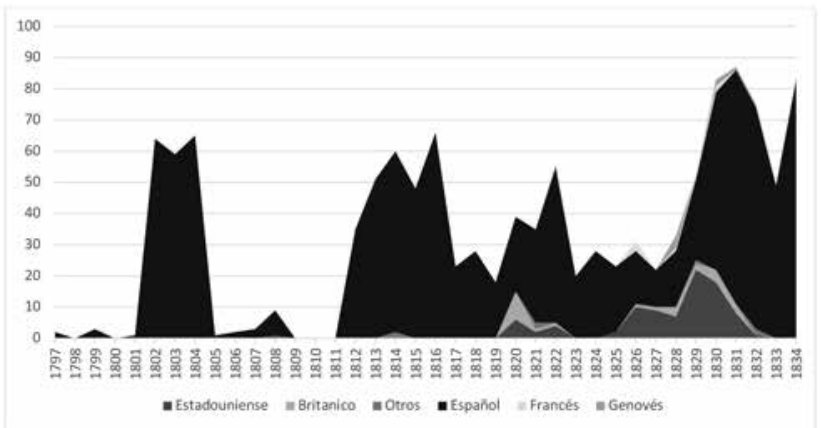

FuENTE: Elaboración propia a partir del Parte semanal de la Vigía de Cádiz, 1798-1808 y 1812-1834.

FiguRA 11. Entradas de buques en el puerto de Cádiz procedentes de Veracruz (reparto en función de sus pabellones), 1798-1834.

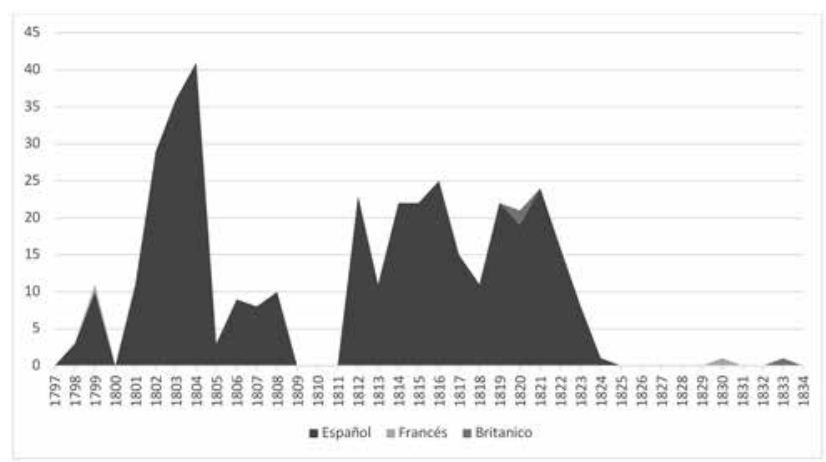

Fuente: Elaboración propia a partir del Parte semanal de la Vigía de Cádiz, 1798-1808 y 1812-1834.

Los primeros territorios emancipados, como los del antiguo Virreinato del Río de la Plata, desaparecieron rápida y completamente, ya en 1815, de la actividad marítima llevada a cabo por los armadores españoles de Cádiz. Cuba, por su parte, no dejó nunca de ser un importante socio comercial de dicho puerto andaluz, incluso durante la década de 1820, si bien el intercambio comercial con la gran Antilla fue realizado cada vez más por buques extranjeros, en lugar de españoles. Un tercer caso fue el del virreinato de la Nueva España, el cual siguió siendo un importante territorio comercial para Cádiz y cuyo tráfico tuvo lugar exclusivamente bajo bandera española hasta 1822. A partir de 1823, sin embargo, México abandonó de forma repentina y permanente los intercambios comerciales con dicho puerto andaluz.

Si se agrega, en definitiva, el comercio con las diferentes provincias americanas, 1822 y 1823 deben ser tomados como los años en que la Carrera de Indias se derrumbó: El número de entradas de barcos procedentes de América pasó de 93 en 1822 (una cifra que 
refleja el patrón de entradas en el período 1812-1822 y que equivale más o menos a dos tercios de los resultados de los mejores años de la historia de la Carrera de Indias) a sólo 32 en 1823 (véase la Figura 12).

FIGURA 12. Entradas de buques en el puerto de Cádiz procedentes de las colonias españolas en América (en número de embarcaciones), 1789-1834.

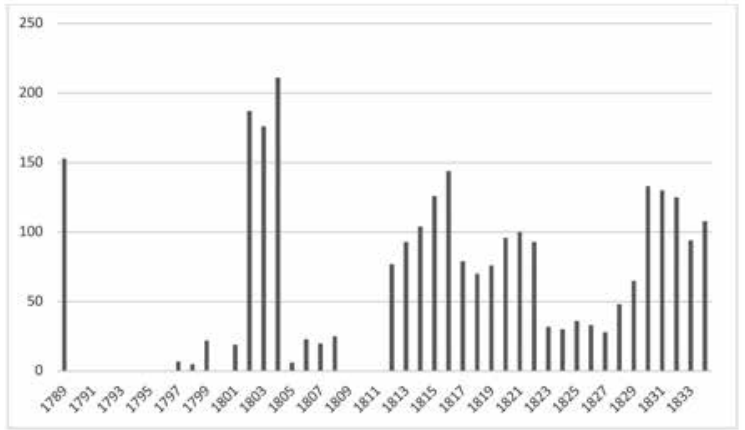

FuENTE: Elaboración propia a partir del Parte semanal de la Vigía de Cádiz, 1789 (colección consultada en los ANP, AE, BIII, 353), 1798-1808 y 1812-1834.

La situación de Cádiz siguió deteriorándose después de 1823. Lo hizo hasta que se concedió la franquicia a dicho puerto, a finales de aquella década, lo que permitió la reanudación de sus relaciones comerciales con las colonias caribeñas. Los informes trimestrales presentados por el cónsul francés en dicha ciudad andaluza, con datos obtenidos a partir de los agentes de aduanas y que tienen la ventaja de proporcionar cifras sobre el volumen del comercio gaditano, confirman exactamente la misma visión que había sugerido el movimiento portuario de la ciudad: el promedio trimestral del comercio colonial gaditano (importaciones y exportaciones combinadas), que había alcanzado un valor de 15 millones de francos en 1820, de 13 millones de francos en 1821 y de 10 millones de francos en 1822, se desplomó repentinamente a 4,5 millones de francos en 1823 y se mantuvo luego en unos 5 millones de francos en 1824 y 1825..$^{21}$ Así que, una vez más, estas cifras del comercio concuerdan con las de la navegación y permitan afirmar que, concretamente, el colapso decisivo de las exportaciones gaditanas a América en 1822 y un año después, en 1823, el mismo fenómeno en el lado de las importaciones. Este último hecho se explica porque las importaciones de metales preciosos se mantuvieron muy altas en 1822, debido probablemente a la repatriación de fondos por parte de los peninsulares que salieron de México durante aquel año.

21. Bartolomei, Arnaud, «Independencias americanas y comercio de Cádiz. Una reconsideración (fin del siglo XVIII-primera mitad del siglo XIX)», en Butrón Prida, Gonzalo (comp.), Las Españas y las Américas: los españoles de ambos hemisferios ante la crisis de independencia, Cádiz, Universidad de Cádiz, 2012, pp. 163-182. 


\section{Regreso al archivo general de Indias}

Otras dos series de datos inéditos de las secciones Arribadas y Ultramar del Archivo General de Indias pueden también incluirse en el análisis. Proceden, por un lado, de los registros de navegación del puerto de Cádiz elaborados por el Tribunal de Arribadas gaditano para el período 1804-1816. ${ }^{22}$ Por otro, de los registros de buques con derecho a comerciar con las Indias, mantenidos por la misma institución, para el período 1817 1822. ${ }^{23}$ Con 732 entradas de barcos de la América Hispana registradas para los años $1815-1816$ y $1818-1822$ y con 541 salidas de barcos con el mismo destino para los años 1815-1816 y 1819-1820 (es decir, con un promedio de 100 entradas al año y con el mismo número anual de salidas), estas dos series validan ampliamente la información del Vigía, aunque las cifras no llegan a coincidir con exactitud (ver Figura 13). ${ }^{24}$

Estas cifras también subrayan la importancia que Veracruz mantuvo en aquel momento en el tráfico portuario de embarcaciones llegadas a Cádiz, ya que 32 barcos habían sido despachados desde allí, en 1819, y otras 45 embarcaciones más, en 1820. Su interés principal radica, no obstante, en otra cuestión, ya que dichos datos también permiten desglosar el tráfico marítimo colonial de Cádiz según los pabellones de los buques que lo realizaban. De esta manera, permiten distinguir la presencia de barcos extranjeros que obtuvieron entonces licencia para comerciar con la América española. Esta práctica está asimismo documentada en otro legajo de la sección de Arribadas, el cual contiene, para los años 1817-1820, la correspondencia del Presidente del Tribunal de Arribadas de Cádiz (Thomás de Barreda) sobre el otorgamiento de licencias a buques extranjeros para navegar legalmente en la Carrera de Indias. ${ }^{25}$ Dicho legajo contiene, entre otras cosas, las cartas enviadas por los armadores gaditanos al presidente de dicho tribunal presentándole las reales órdenes que habían obtenido de la Corte y exhortándole para que haga las gestiones necesarias ante las autoridades aduaneras del puerto. El legajo también contiene varias cartas intercambiadas entre Barreda y José de Imaz, el Ministro de la Hacienda de Indias, en Madrid, quien había distribuido las susodichas licencias a los diversos solicitantes. Aquellos intercambios permiten comprender mejor, en definiti-

22. Archivo General de Indias (AGI), Arribadas, 361, «Buques que han entrado en este puerto [Cádiz], procedentes de los de Indias desde $1^{\text {ero }}$ de enero de 1804 hasta 31 de diciembre de $1816 »$, «Buques que han salido de este puerto [Cádiz] para los de Indias desde $1^{\text {ero }}$ de enero de 1804 hasta 31 de diciembre de 1816». El Tribunal de Arribadas es la institución que heredó de las atribuciones de la Casa de la Contratación después de su supresión en 1790 (Muñoz Pérez, José, «La supresión de la Casa de la Contratación de Cádiz, 1790-1793», Cádiz en su historia, II Jornadas de Historia de Cádiz, Cádiz, Caja de Ahorros de Cádiz, 1983, pp. 91-123).

23. AGI, Arribadas, 368, libro registro de las aperturas de registros y entrada y salida de buques para ultramar, Cádiz, 1817-1822.

24. Las cifras casi nunca coinciden exactamente, pero al final, considerando los 15 años para los cuales podemos comparar los datos de las dos fuentes, la diferencia aparece como mínima pues se recogieron 1334 entradas de navíos en los registros del Tribunal de Arribadas y 1264 en las estadísticas anuales publicadas por el Vigía.

25. AGI, Arribadas, 354, Ordenes, oficios y comunicaciones desde la Secretaría de Indias al Juzgado de Arribadas de Cádiz sobre permisos de navíos extranjeros para Ultramar, 1817-1820. 
va, la cronología específica de aquella práctica así como la resistencia que la misma suscitó en Cádiz.

FiguRa 13. Movimiento portuario de Cádiz según los datos del Vigía y del Tribunal de Arribadas (1804-1822).

\begin{tabular}{|c|c|c|c|}
\hline & $\begin{array}{c}\text { ENTRADAS DE AMÉRICA } \\
\text { (VIGÍA) }\end{array}$ & $\begin{array}{c}\text { ENTRADAS DE AMÉRICA } \\
\text { (ARRIBADAS) }\end{array}$ & $\begin{array}{c}\text { SALIDAS A AMÉRICA } \\
\text { (ARRIBADAS) }\end{array}$ \\
\hline 1804 & 211 & 213 & 151 \\
\hline 1805 & 6 & 5 & 60 \\
\hline 1806 & 23 & 17 & 33 \\
\hline 1807 & 20 & 16 & 58 \\
\hline 1808 & 25 & 31 & 76 \\
\hline 1809 & & 262 & 215 \\
\hline 1810 & & 236 & 183 \\
\hline 1811 & & 133 & 105 \\
\hline 1812 & 77 & 93 & 76 \\
\hline 1813 & 93 & 105 & 134 \\
\hline 1814 & 104 & 122 & 85 \\
\hline 1815 & 126 & 133 & 238 \\
\hline 1816 & 144 & 151 & 106 \\
\hline 1817 & 79 & & \\
\hline 1818 & 70 & 85 & \\
\hline 1819 & 76 & 112 & 84 \\
\hline 1820 & 96 & 109 & 111 \\
\hline 1821 & 100 & 100 & \\
\hline 1822 & 93 & 42 & \\
\hline
\end{tabular}

FUENTE: Elaboración propia a partir del Parte semanal de la Vigía de Cádiz, 1804-1822 (colección consultada en la Biblioteca de Temas Gaditanos, Cádiz) y AGI, Arribadas, 361, «Buques que han entrado en este puerto [Cádiz], procedentes de los de Indias desde $1^{\text {ero }}$ de enero de 1804 hasta 31 de diciembre de 1816», «Buques que han salido de este puerto [Cádiz] para los de Indias desde $1^{\text {ero }}$ de enero de 1804 hasta 31 de diciembre de 1816» y Arribadas, 368, libro registro de las aperturas de registros y entrada y salida de buques para ultramar, Cádiz, 1817-1822.

Esta documentación pone de relieve que la navegación con licencia, una práctica inexistente en 1817, creció rápidamente en importancia durante 1818 (20 licencias concedidas sólo para el puerto de Cádiz), antes de alcanzar un máximo en 1819 (32 licencias concedidas para Cádiz). El año siguiente, 1820, desapareció rápidamente, debido a la suspensión de aquel procedimiento por el nuevo gobierno liberal. ${ }^{26}$ No obstante, dicha serie no parece ser exhaustiva, y tanto el Vigía como los registros del Tribunal de Arribadas atestiguan el hecho de que muchos barcos extranjeros siguieron navegando entre

26. Las licencias que ya habían sido otorgadas fueron utilizadas en el corriente del primer semestre del año siguiente. 
Cádiz y América durante los dos primeros años del Trienio Liberal. En total, según dichos registros, los buques extranjeros con licencia para viajar al Nuevo Mundo habrían representado casi la cuarta parte del tráfico americano de Cádiz en aquella época: 22 de los 84 buques que salieron de Cádiz con destino a América en 1819 y 23 de los 112 buques que entraron en el puerto en aquel mismo año; luego 19 salidas (de un total de 111) y 23 entradas (de un total de 109) en 1820; y 14 buques extranjeros ( 8 americanos, 4 británicos y 2 suecos) de las 100 entradas registradas en $1821 .^{27}$ El vaciado del Vigía en torno a los buques de bandera extranjera despachados rumbo a la América hispana ofrece cifras bastante similares, aunque algo diferentes: 21 entradas en 1819, 30 en 1820 y 23 en 1821. En otros puertos españoles, el fenómeno debió ser aún más importante, pero en la actualidad no tenemos datos cuantitativos tan completos como los que disponemos para Cádiz.

Más allá de la cuestión de la importancia exacta de dicha navegación extranjera «bajo licencia», que fue autorizada en aquel momento tan particular de la Carrera de Indias, lo realmente importante para mis propósitos es señalar que dicho tráfico afectó a Veracruz sólo de forma muy marginal. Aunque dicho puerto se menciona en ocho permisos concedidos a los armadores gaditanos en la primavera de 1819, no vuelve a mencionarse después de aquella fecha, e incluso algunos permisos posteriores consignan expresamente que ya no se permitía la entrada de barcos extranjeros en aquel puerto mexicano. ${ }^{28}$ En total, el número de barcos extranjeros que navegaron legalmente entre Cádiz y Veracruz parece haber sido mínimo: el Vigía registra sólo dos entradas de barcos británicos en 1820 y los registros del Tribunal de Arribadas mencionan sólo tres embarques en 1819 y tres entradas en 1820.

\section{Otros puntos de vista en Europa}

Las reconstrucciones cuantitativas que pueden hacerse sobre el comercio directo registrado entonces entre Europa y México, a partir de fuentes gaditanas y veracruzanas, deben ser analizadas como reconstrucciones parciales, ya que excluyen, por su naturaleza, la navegación registrada desde otros puertos españoles autorizados (en particular Barcelona y Málaga) o en puertos mejicanos otros que Veracruz (como Campeche, Tampico o San Blas, por ejemplo). Además, todas estas fuentes ignoran el intercambio mercantil que tuvo lugar fuera del marco legal del libre comercio. Por consiguiente, es útil realizar una última serie de comprobaciones incorporando el papel de distintos puertos europeos y, singularmente, de aquellos que desempeñaban un papel fundamental en el abastecimiento del comercio mexicano desde Cádiz durante el período colonial. Así

27. AGI, Arribadas, 368, libro registro de las aperturas de registros y entrada y salida de buques para ultramar, Cádiz, 1817-1822.

28. AGI, Arribadas, 354, Ordenes, oficios y comunicaciones desde la Secretaría de Indias al Juzgado de Arribadas de Cádiz sobre permisos de navíos extranjeros para Ultramar, 1817-1820. 
podremos determinar mejor cuándo comenzaron a establecer relaciones directas de dichos puertos europeos con América, una tarea particularmente difícil y tediosa dada la dispersión de las fuentes. Los primeros sondeos realizados, sin embargo, desde los observatorios de Marsella, Génova y Hamburgo (tres puertos que enviaban una veintena de barcos al año a Cádiz en la década de 1780), confirman totalmente la opinión ya expuesta. ${ }^{29}$

Así, mientras que el cónsul español en Marsella menciona por primera vez, en 1817, la llegada de dos barcos procedentes de Buenos Aires, el hecho parece seguir siendo bastante anecdótico en los años inmediatamente posteriores. ${ }^{30}$ Una estadística, por ejemplo, de la primera mitad de 1823, publicada por un periódico mercantil de Marsella, revela las siguientes cifras: de los aproximadamente 2.147 barcos que entraron o salieron del puerto entre el 1 de enero y el 1 de julio, sólo 49 tenían como destino o procedían de América, de los cuales sólo un tercio procedía de la América hispana (15) y sólo uno procedía directamente de México (Campeche). ${ }^{31}$ Es cierto que Marsella ya no era el puerto francés mejor situado para el desarrollo de aquel comercio directo con la América hispana dado que Burdeos se venía afirmando, desde hace varios años, como el nuevo centro del comercio francés con las colonias españolas en América. Los archivos del consulado español en Burdeos atestiguan este papel creciente de ese importante puerto de Aquitania en los intercambios directos registrados entre Europa e Hispanoamérica. En febrero de 1815, por ejemplo, el cónsul español en Burdeos mencionó viajes regulares de barcos despachados rumbo a La Habana y, tres años más tarde, los registros de embarque del segundo trimestre de 1818 informan que 14 barcos salieron de Burdeos hacia La Habana, durante aquellos seis meses, con casi 1,3 millones de francos de mercancías francesas. Dichos registros informan también que 11 embarcaciones regresaron a Burdeos desde la capital cubana, con diversas mercancías (fundamentalmente azúcar y café) por valor de 2,38 millones de francos, unas mercaderías que fueron casi inmediatamente reexportadas a diferentes puertos del norte de España. Pero La Habana es innegablemente un caso especial. ${ }^{32}$ Así, el mismo cónsul español, al que se le preguntó en 1815 sobre el alcance de estos vínculos directos entre Burdeos y el imperio español, respondió: «Resulta no haberse hecho más expedición en buque francés que uno con destino a La Guaira (pero cargado de géneros franceses) y por no haberlo recibido en

29. En 1789, Cádiz recibió 40 navíos provenientes desde Marsella, 25 de Hamburgo y 13 de Génova, casi todos cargados con géneros destinados a los mercados coloniales americanos (Bartolomei, Arnaud, Cadix et la Méditerranée..., cit., pp. 203-205).

30. Archivo Histórico Nacional (AHN), Estado, 6208, Marsella, 4, correo del 13 de abril de 1817.

31. Archives de la Chambre de Commerce de Marseille-Provence (ACCMP), n. ${ }^{\circ} 152$, Feuille de commerce, nouvelles maritimes, affiches, annonces judiciaires et avis divers, Marseille, 1 de julio de 1823.

32. AHN, Estado, 6161, Burdeos, 2, correo del 17 febrero 1815. Archivo General de la Administración (AGA), Burdeos, 029, 54/3210, correo del 31 diciembre 1818: «Buques entrados en este puerto en los últimos seis meses de este año de 1818 con cargamento de azúcar y café procedentes de La Havana», «Estado de los buques franceses que han salido de Burdeos para La Havana en los seis últimos meses del año 1818 con géneros franceses: paños, telas, vinos, muebles, sederías, relojería, etc., según las declaraciones existentes en el archivo de este consulado». 
aquel puerto, fue a La Havana, donde logró descargar sus géneros».33 Tres años después, en 1818, la situación apenas había variado: aunque una casa española obtuvo permiso para armar en Burdeos un barco francés para ir a buscar cacao a La Guaira, aquel permiso se dio con la condición de que el viaje de regreso finalizara en un puerto español y que se depositara una garantía financiera. ${ }^{34}$ Aquel mismo año, además, el embajador español en París solicitó una audiencia con el duque de Richelieu para discutir la llegada a Burdeos de un barco francés procedente de Buenos Aires. ${ }^{35}$ No parece pues que se hubiera establecido entonces la práctica de viajes directos entre los puertos de Francia y de la América hispana.

En Génova, las relaciones directas con América también parecen haber comenzado después de 1820. En aquel año, los informes comerciales elaborados por el cónsul español en dicha ciudad atestiguan que el comercio entre el puerto de Liguria y la América hispana siguió pasando abrumadoramente por Cádiz: aunque la ciudad recibió algo de índigo de La Guaira y de azúcar de La Habana, la cochinilla importada a través de Cádiz sigue representando un tercio del total de las importaciones desde España, y el papel exportado en sentido contrario representa el $15 \%$ del total de las exportaciones ligures a los puertos españoles. ${ }^{36}$ Además, hasta 1824, el número de barcos sardos que entraban en el puerto de Buenos Aires nunca superó los 7 (mientras llegó a 43 en 1834). ${ }^{37}$ La situación era muy similar en Hamburgo. En 1818, el cónsul español que allí residía se refirió a la considerable importancia del comercio directo con la América hispana para dicho puerto aunque señaló que «hallándose prohibido por las leyes de Indias el comercio extranjero en aquellos Dominios, con solo la moderna excepción a favor de la Habana..., de estos puertos no sale absolutamente buque alguno para los dominios de Indias sino para la Habana y algún puerto de la Isla de Cuba». ${ }^{38}$ En efecto, en la segunda mitad de 1819, Cádiz y La Habana seguían jugando en igualdad de condiciones como salidas para las exportaciones alemanas: cada uno de los dos puertos recibió entonces 7 barcos despachados desde Hamburgo y el primero recibió 708 cajas de telas mientras que al segundo llegaron 783. ${ }^{39}$ Tres años más tarde, sin embargo, la situación había cambiado radicalmente: aquel año Hamburgo envió 27 barcos a La Habana mientras que despachó únicamente 7 buques (cargados con sólo 100 marcos de telas) para Cádiz..$^{40} \mathrm{El}$ primer buque despachado para Veracruz, el barco danés La Perle, comandado por el capitán Hans Brunhe, se

33. AHN, Estado, 6161, Burdeos, 2, correo del 10 de marzo de 1815.

34. Ibidem, 1, correo del 11 de octubre de 1818.

35. Ibidem, Burdeos, 1, correo del 22 de agosto de 1818.

36. AHN, Estado, 6182, Génova, correo del 19 de diciembre 1820, «Estado activo y pasivo, de los géneros y su valor, que se han embarcado en el puerto de Génova para España, y viceversa, en el primer semestre del año $1820 »$.

37. Brilli, Catia, «Da Cadice a Buenos Aires: crisi e rinascita del commercio ligure nella nuova configurazione dell'Atlantico iberico (1797-1837)», Annali della Fondazione Luigi Einaudi, n. ${ }^{\circ}$ XLII, Torino, 2008, p. 109.

38. AHN, Estado, 6190, Hamburgo, correo del 7 de febrero de 1818.

39. Ibidem, correo del 22 de enero de 1820.

40. Ibidem, correo del 9 de agosto de 1822 . 
menciona en una carta de febrero de 1822, aunque no llegó a su destino. ${ }^{41}$ Parece que no fue hasta 1824 cuando hubo barcos mercantes que navegaron directamente entre Hamburgo y América (despachados, en este caso, a Puerto Cabello y a Buenos Aires), sin hacer escala en La Habana. ${ }^{42}$ No disponemos de datos similares para los puertos británicos, pero las cifras sobre la balanza comercial del Reino Unido con la América española sugieren que la situación debe haber sido diferente: después de 1815, el monto total de las exportaciones británicas a España se redujo drásticamente, lo que sugiere que las mercancías destinadas a la América española se enviaban ahora allí directamente, a menos que se desviaran a Gibraltar, puerto que en aquel momento estaba absorbiendo una parte cada vez mayor del comercio que antes se realizaba a través de Cádiz.

Así pues, aparte de esta última excepción, los datos que emanaban de los distintos puertos europeos coinciden con la imagen que daban las fuentes americanas y españolas: si el puerto de La Habana se abrió temprana y masivamente a los pabellones extranjeros, incluso antes de los decretos de 1818, los demás puertos del imperio, y en particular el de Veracruz, permanecieron cerrados a la navegación extranjera durante mucho más tiempo, a veces incluso varios años después de que los territorios a los que servían hubiesen obtenido la independencia. ${ }^{43}$

\section{Veracruz, un puerto cerrado}

Según las cifras proporcionadas por las balanzas comerciales elaboradas por Quirós, el puerto de Veracruz sólo recibió cantidades importantes de mercancías importadas directamente de puertos extranjeros en tres años: en 1806, 1807 y 1808. Aquellos tres años representaron, en conjunto, casi el $85 \%$ de las mercancías importadas legalmente del extranjero a través de dicho puerto entre 1796 y 1820 (18,5 millones de pesos fuertes sobre un total de 22 millones), lo que permite afirmar que la apertura legal de Veracruz resultó finalmente, durante todo aquel período, un fenómeno muy puntual y controlado. Así pues, cuando las alianzas se invirtieron después de 1808, el tráfico con los puertos extranjeros neutrales, que había florecido durante los tres años anteriores, cesó inmediatamente y el tráfico con los puertos españoles experimentó, por el contrario, un creci-

41. Ibidem, correos del 26 de febrero de 1822 y del 9 de abril de 1822. Al llegar a Veracruz fue desviada porque el gobernador del baluarte de San Juan de Ulúa no le dejó entrar en el puerto.

42. Ibidem, correo del 30 de marzo de 1824.

43. En 1816, dentro de los 1098 navíos entrados en el puerto de La Habana, 456 llevaban el pabellón español y 642 un pabellón extranjero. Archives du Ministère des Affaires étrangères - La Courneuve, Correspondance Consulaire Commerciale (AMAE-LC, CCC, 152-2, 7, «Rapport à Son Excellence M. Hyde de Neuville», Guillaumin, s/f). En 1820, Cádiz seguía siendo, con 51 unidades de las 1368 entradas de navíos en el puerto de La Habana, el primer puerto europeo (y el octavo, en total, detrás de siete puertos americanos) dentro de los contactos del puerto cubano. Pero, ya ocho otros puertos europeos habían expedido más de 15 navíos a Cuba aquel año: Burdeos (24 unidades), Marsella (23), Bristol (20), Bath (20), Liverpool (18), Portsmouth (18), Hamburgo (15) y Londres (15). Ver AMAE - LC, CCC, 152-2, 41, «Tableau des bâtiments entrés dans le port de La

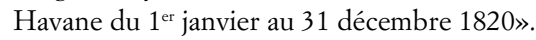


miento muy fuerte, pasando de tres millones de pesos fuertes en 1808 a 17 millones en 1809. Las estadísticas del «derecho de agua», que registraron sólo 9 buques de puertos extranjeros para el período 1790-1821 (aunque subestimen probablemente la realidad), confirman también la idea general de que, hasta principios del decenio de 1820, los buques de Europa o América del Norte que anclaron abiertamente en el puerto fueron muy escasos, si no estrictamente anecdóticos. Prueba de ello son las desventuras de Hans Brunhe, capitán del barco danés La Perla, que se acondicionó en Hamburgo para Veracruz en 1821 y tuvo que renunciar a entrar en dicho puerto por la oposición del gobernador español del Fuerte de San Juan de Ulúa.

Cerrado al comercio directo con los puertos extranjeros, Veracruz estaba también cerrado, en buena medida, al intercambio comercial con las otras colonias hispanoamericanas. Ciertamente, las estadísticas elaboradas por Robert Smith indican que uno de cada dos barcos que entraron en dicho puerto durante el período analizado procedía de otro puerto americano. Pero, en total, los muchos barcos que habían zarpado desde La Habana, desde Nueva Orleans (hasta 1802), desde otros puertos mexicanos o desde Venezuela llevaron sólo una quinta parte de las mercancías importadas por Veracruz. Constituidos principalmente por materias primas agrícolas de las regiones de las que procedían (cera y miel cubana, cacao venezolano), los cargamentos de todos aquellos barcos fueron en realidad de mucho menos valor que los ricos cargamentos de telas, de origen europeo o español, importados de Cádiz. El mismo fenómeno se observó también en España: con el tiempo, el tráfico de los puertos de Barcelona y Málaga llegó a igualar al de Cádiz en cuanto al número de buques, pero el valor de las cargas gaditanas era muy superior al de los buques catalanes, que transportaban principalmente vino y aguardiente, lo que explica que el monopolio de Cádiz nunca se vio realmente socavado por las reformas comerciales adoptadas por la Corona a partir de 1778. En definitiva, a pesar de los temores reiterados por los consulados de Cádiz y de Veracruz sobre la apertura cada vez mayor de La Habana, y a pesar de la creciente tolerancia del comercio intracolonial, sólo una pequeña parte de la gran cantidad de mercancías exportadas directamente desde Europa a La Habana pudo entrar legalmente en el puerto de Veracruz. ${ }^{44}$

En cuanto al comercio que se realizaba desde Cádiz, permaneció durante todo el período analizado casi exclusivamente en manos de los armadores de dicha ciudad y de la marina mercante española, a pesar incluso de que la actividad corsaria de los insurgentes había tenido como principal objetivo el susodicho puerto andaluz, sus barcos y sus mercaderes. Cabe mencionar que diez buques de bandera extranjera fueron autorizados a navegar entre Cádiz y Veracruz durante los años 1818 y 1819 (en casi todos los casos con una escala prevista en La Habana). Es importante señalar, sin embargo, que aquellas licencias fueron sólo un pequeño número de las que se concedieron al puerto de Cádiz durante el período en cuestión, que su concesión cesó repentinamente en 1819 (aunque

44. Según Javier Ortiz de la Tabla, sólo un tercio de las importaciones intraamericanas de Veracruz consistió en reexportaciones de productos europeos, introducidos a través de algún otro puerto colonial español, por un monto de 16 millones de pesos (Ortiz de la Tabla, Javier, Comercio exterior de Veracruz..., cit., p. 124). 
se mantuvieron hasta el establecimiento del gobierno liberal para los demás puertos americanos) y, por último, que estas licencias se concedieron exclusivamente a armadores y fletadores españoles, casi siempre del comercio gaditano, de los que no hay pruebas de que pudieran haber sido meros testaferros de comerciantes extranjeros.

Las descripciones del puerto de Veracruz de la época se encuentran, además, en las antípodas del ideal-tipo del «Port of Trade» polanyano..$^{45}$ No se permitió que ningún cónsul extranjero se estableciera en la ciudad hasta la declaración de independencia, y los pocos extranjeros que allí lograron establecerse lo hicieron bajo identidades ocultas. Así, ninguno de los dos principales actores en los negocios del llamado «Contrato OuvrardHope-Baring» se estableció abiertamente en Veracruz: Vincent Nolte tenía su base en Nueva Orleans mientras que su socio en Veracruz, el francés Armand Pierre Lastapis, se había dado a conocer allí con el nombre falso de Gabriel de Villanueva. ${ }^{46}$ En cuanto a la otra figura de la época que se distinguió en el comercio de Veracruz con los países neutrales, y más tarde con el Reino Unido, Tomás Murphy, aunque tenía ascendencia británica, había nacido en Málaga y gozaba de todos los derechos de la naturaleza española. ${ }^{47}$ Así, aunque el comercio de neutrales pudo haber favorecido a algunas figuras cosmopolitas en la plaza de Veracruz, todos los estudios prosopográficos dedicados a su estudio coinciden en destacar la hegemonía de que gozaron los españoles peninsulares (especialmente los vascos y los montañeses) hasta su expulsión en 1828 y $1829 .{ }^{48}$

\section{Conclusiones: dos hipótesis para explicar la resistencia del eje Cádiz-Veracruz}

Todas las fuentes aquí citadas y consultadas, tanto las mexicanas como las gaditanas o las europeas, sean «oficiales» o «alternativas», confirman la resistencia a las dificultades de aquel tiempo mostrada por los vínculos marítimos y comerciales que unieron a Veracruz y Cádiz hasta 1822. Confirman asimismo que dicho comercio siguió siendo, a lo largo del período analizado, una especie de «coto» para la marina mercante española y para sus principales actores (mercaderes de México y Veracruz, cargadores de Cádiz y armado-

45. Addobbati, Andrea, «L'espace de la guerre et du commerce: réflexions sur le Port of Trade polanyien à partir du cas de Livourne», Cabiers de la Méditerranée, n. ${ }^{\circ}$ 85, Nice, 2012, pp. 233-250, <https://doi.org/ $10.4000 / \mathrm{cdlm} .6751>$.

46. Jiménez Codinach, Guadalupe, «El comercio clandestino, 1797-1811», en Yuste López, Carmen y Matilde Souto Mantecón (comps.), El comercio exterior de México (1713-1850), México, Veracruz, Instituto de Investigaciones José María Luis Mora, UNAM, Universidad Veracruzana, 2000, pp. 193-206.

47. Marichal, Carlos, «El comercio neutral y los consorcios extranjeros en Veracruz, 1805-1808», en Yuste López, Carmen y Matilde Souto Mantecón (comps.), El comercio exterior de México (1713-1850), México, Instituto de Investigaciones José María Luis Mora, Instituto de Investigaciones Históricas, Universidad Nacional Autónoma de México, Universidad Veracruzana, 2000, pp. 163-192. González Mireles, Gabriela Sofía, La trayectoria de Tomás Murphy Porro: cambios y permanencias en las élites económicas del virreinato en el México independiente, Tesis de Doctorado, Universidad Nacional Autónoma de México, 2014.

48. Booker, Jackie R., Veracruz Merchants, 1770-1829. A Mercantile Elite in Late Bourbon and Early Independent Mexico, Oxford, Westview Press, 1994. Souto Mantecón, Matilde, Mar abierto..., cit. 
res). Y sugieren también, por último, algunas pistas para una futura reflexión, pistas que deberán ser exploradas con mayor profundidad, a la hora de explicar las razones de aquella inesperada y poco frecuente resistencia del sistema monopolístico español. Dos parecen haber sido las razones más relevantes: por un lado, la solidez e influencia (por no decir la eficacia) de las instituciones encargadas de administrar el comercio colonial español y de protegerlo de la intrusión extranjera, a saber, los consulados de Cádiz, Ciudad de México y Veracruz; por otro lado, la fuerza de las redes comerciales que los comerciantes peninsulares habían logrado construir a ambos lados del Océano Atlántico.

La primera de estas hipótesis es la más documentada por la historiografía y las fuentes. El papel que desempeñó el Consulado de Cádiz en defensa del monopolio es ya muy conocido. Por ejemplo, por las presiones que ejerció sobre los Cortes, contribuyó decisivamente al rechazo de los proyectos de apertura de los puertos americanos a los aliados ingleses que se habían fomentado en los círculos de la Junta Central o de la Regencia en los años 1808-1811.49 Por supuesto, todos sus proyectos de restauración del monopolio, que abundan en los fondos públicos españoles, no encontraron éxito. ${ }^{50}$ Pero supo aprovecharse del papel central que asumió en el financiamiento del esfuerzo militar metropolitano de reconquista de América a través de la Comisión de Reemplazo que fue creada precisamente en 1811 en su seno. ${ }^{51}$ De hecho, los barcos armados para transportar las tropas a América sirvieron también para proteger convoyes mercantes de las agresiones de los corsarios insurgentes y permitieron así el mantenimiento de las relaciones marítimas que se destacan en las fuentes. ${ }^{52}$ También en América, los Consulados de México y Veracruz actuaron en el mismo sentido luchando en contra de la apertura del puerto de Veracruz a los extranjeros o obstaculizando el comercio de reexportación de las mercancías europeas que se practicaba desde La Habana. ${ }^{53}$ Beneficiaron para eso de la complicidad nunca desmentida del último virrey de la Nueva España, Apodaca, que hasta el final, mantuvo la aplicación de las leyes de Indias en los territorios situados bajo su jurisdicción. ${ }^{54}$ Después de la proclamación de independencia de Méjico, los actores tradicionales del monopolio pudieron seguir contando con el apoyo de los comandantes militares del baluarte de San Juan de Ulúa, que sólo capituló en 1825.55

La segunda hipótesis nos acerca más de una historia social de la Carrera de Indias y del protagonismo que tenían en su funcionamiento las redes mercantiles uniendo los co-

49. Chávez Orozco, Luis, La libertad del comercio en la Nueva España en la segunda década del siglo XIX, México, Secretaría de Hacienda y Crédito público, 1943, p. 47 y siguientes.

50. Ver, por ejemplo, Archivo Histórico Provincial de Cádiz (AHPC), Purullena, 28, 27, «Cargos administrativos y políticos», «Copia de la contestación del Consulado de Cádiz al interrogatorio que de Real Orden le remitió el ministro de Hacienda», Cádiz, 30 de marzo de 1819.

51. Malamud, Carlos, Sin marina, sin tesoro..., cit., passim.

52. Ruiz García, Vicente, Las naves de las Cortes (1808-1812). El último servicio de la Marina de la Ilustración, Madrid, Sílex, 2013.

53. Tandrón, Humberto, El comercio de Nueva España y la controversia sobre la libertad de comercio, 17961821, México, Instituto Mexicano de Comercio Exterior, 1976, p. 105.

54. Chávez Orozco, Luis, La libertad del comercio en la Nueva España, cit., p. 136.

55. AGI, México, 1148b, Consulta del Consejo de Indias, 17 de agosto de 1824 
merciantes españoles de las dos orillas del Atlántico. La lectura de sus correspondencias comerciales, conservadas en diversos fondos de España o de Méjico, permite subrayar que aquellos comerciantes peninsulares, que se apoyaban en redes familiares diseminadas en ambos lados del Atlántico, seguían estando muy bien situados para facilitar los intercambios comerciales entre Veracruz y Europa.$^{56}$ De hecho mantenían contactos muy estrechos, por la intermediación de los Consulados o por sus propias redes personales, con los agentes de la corona encargados de la regulación de la Carrera de Indias, lo que les permitió aprovecharse de facilidades administrativas a las cuales no tenían acceso sus competidores. Pero, aun más, beneficiaban de un conocimiento fino del funcionamiento de los mercados mejicanos, de los gustos de los consumidores y de los usos locales. Poseían contactos directos con los tenderos, viandantes y arrieros que eran intermediarios imprescindibles para acceder a los mercados del país y sabían, por la experiencia acumulada desde décadas, cuáles eran los buenos socios y los ritmos específicos del comercio local para vender y comprar en las mejoras condiciones. Eso fue una ventaja decisiva que benefició a los mercantes españoles y que solo perdieron cuando la coyuntura política les prohibió el acceso al mercado mejicano - a saber, en los años que siguieron la proclamación de independencia para los cargadores gaditanos y hasta los años 1828 y 1829 para los peninsulares que se habían quedado en Méjico después de 1821 y que fueron expulsados del país en aquellos años.

En conjunto, estas conclusiones conducen a un cuadro algo diferente de la visión habitualmente muy crítica y autodespreciativa - por no decir dolorista- que los historiadores han tendido a ofrecer sobre los actores del comercio colonial español, sobre las instituciones que lo gobernaron y, más en general, sobre el sistema imperial construido por la monarquía hispana. De hecho, la perspectiva general que nos dan nos llevan a invertir la cadena de acontecimientos que Antonio García-Baquero defendió en su día: No fue la ineficiencia económica de la Carrera de Indias, revelada de manera contingente durante los enfrentamientos políticos y militares que se sucedieron a partir de 1796, la que provocó la quiebra del imperio colonial español, sino la crisis política, que culminó con las proclamaciones de independencia de México y Perú en 1821, la que puso fin a un sistema de comercio que durante tres siglos había sido el principal sostén de los intercambios que vinculaban a productores y consumidores de Europa y de la América Hispana.

56. Para el estudio más amplio que estamos realizando sobre el asunto, hemos utilizado el fondo Yraeta conservado en Méjico (Acervo Histórico de la Universidad Iberoamericana (AHUI), Fondo Compañía de Francisco Ignacio de Yratea, 2.1.64-65, Registros de Correspondencia), el fondo Iribarren conservado en Cádiz (AHPC, Archivo del Marqués de Purullena, 26, 15, «Libro primero copiador de correspondencia a distintos corresponsales, 1798-1806») y varios corpus de correspondencia localizados en el Archivo General de Indias (AGI, Consulados, 521, «Correspondencia dirigida à don Martin José de Camio (1819-1831)» y en el Archivo General de la Administración de Alcalá de Henares (AGA, Burdeos, 029, 54/3212, Papeles diversos del cónsul de España a Burdeos, correos expedidos a José de Arze, 1818-1819). 


\section{Archivos consultados}

Archivo General de Indias (AGI), Sevilla, España.

Archivo Histórico Nacional (AHN), Madrid, España.

Archivo General de la Administración (AGA), Alcalá de Henares, España.

Archivo Histórico Provincial de Cádiz (AHPC), Cádiz, España.

Acervo Histórico de la Universidad Iberoamericana (AHUI), Ciudad de México, México.

Archives Nationales de Paris (ANP), Paris, Francia.

Archives du Ministère des Affaires Étrangères de La Courneuve (AMAE-LC), La Courneuve, Francia.

Archives de la Chambre de Commerce de Marseille-Provence (ACCMP), Marsella, Francia.

\section{Bibliografía}

Addobbati, Andrea, «L'espace de la guerre et du commerce: réflexions sur le Port of Trade polanyien à partir du cas de Livourne», Cahiers de la Méditerranée, n. ${ }^{\circ}$ 85, Nice, 2012, pp. 233-250, $<$ https://doi.org/10.4000/cdlm.6751>.

Alfonso Mola, Marina, «1828. El fin del libre comercio», en Martínez Shaw, Carlos, José María Oliva Melgar (comps.), El sistema atlántico español (siglos XVII-XIX), Madrid, Marcial Pons, 2005, pp. 311-349.

—, «El tráfico marítimo de la Carrera de Indias en las agitadas aguas de las independencias», en Silva, Hernán Asdrúbal (comp.), Historia económica del cono sur de América. Argentina, Bolivia, Brasil, Chile, Paraguay y Uruguay. La era de las revoluciones y la independencia, México, Instituto Panamericano de Geografía e Historia, 2010, pp. 93-179.

Bartolomei, Arnaud, «Cadix et la Méditerranée à la fin du XVIII siècle», Revue d'Histoire Maritime, n. ${ }^{\circ}$ 13, Paris, 2011, pp. 173-209, <https://halshs.archives-ouvertes.fr/halshs-03156661/document>.

—, «Independencias americanas y comercio de Cádiz. Una reconsideración (fin del siglo XVIII-primera mitad del siglo XIX)», en Butrón Prida, Gonzalo (comp.), Las Españas y las Américas: los españoles de ambos hemisferios ante la crisis de independencia, Cádiz, Universidad de Cádiz, 2012, pp. 163-182.

—, Les marchands français de Cadix et la crise de la Carrera de Indias (1778-1828), Madrid, Casa de Velázquez, 2017.

Bernal, Antonio Miguel (comp.), El comercio libre entre España y América: 1765-1824, Madrid, Fundación Banco Exterior, 1987.

—, España, proyecto inacabado, Los costes-beneficios del imperio, Madrid, Centro de Estudios Hispánicos e Iberoamericanos, Marcial Pons Historia, 2005.

Booker, Jackie R., Veracruz Merchants, 1770-1829. A Mercantile Elite in Late Bourbon and Early Independent Mexico, Oxford, Westview Press, 1994.

Brilli, Catia, «Da Cadice a Buenos Aires: crisi e rinascita del commercio ligure nella nuova configurazione dell'Atlantico iberico (1797-1837)», Annali della Fondazione Luigi Einaudi, n. ${ }^{\circ}$ XLII, Torino, 2008, p. 109.

Chaunu, Pierre, «Interprétation de l'indépendance de l'Amérique latine», Bulletin de la Faculté de Lettres de Strasbourg, n. ${ }^{\circ}$ 8, Strasbourg, 1963, pp. 403-421. 
Chávez Orozco, Luis, La libertad del comercio en la Nueva España en la segunda década del siglo XIX, México, Secretaría de Hacienda y Crédito público, 1943.

Delgado Ribas, José María, Dinámicas imperiales (1650-1796): España, América y Europa en el cambio institucional del sistema colonial español, Barcelona, Bellatera, 2007.

Fisher, John R., Commercial Relations between Spanish and Spanish America in the Era of Free Trade, 1778-1796, Liverpool, The University of Liverpool, 1985.

—, El comercio entre España e Hispanoamérica: 1797-1820, Madrid, Banco de España, 1993.

Gamez Duarte, Feliciano, Luchar contra el mar, edificar en el viento. La Compañia gaditana Viniegra, 1797-1829, Cádiz, Ayuntamiento de Cádiz, 1999.

-, Del uno al otro confín. España y la lucha contra el corso insurgente hispanoamericano, Cádiz, Diputación de Cádiz, 2008.

García-Baquero Gónzalez, Antonio, Comercio colonial y guerras revolucionarias. La decadencia económica de Cádiz a raíz de la emancipación americana, Sevilla, Publicaciones de la Escuela de Estudios Hispano-Americanos de Sevilla, 1972

-, «Los resultados del libre comercio y «el punto de vista»: una revisión desde la estadística», Manuscrits, n. ${ }^{\circ} 15,1997$, pp. 303-322.

-, El libre comercio a examen gaditano. Crítica y opinión en el Cádiz mercantil de fines del siglo XVIII, Cádiz, Universidad de Cádiz 1998.

González Mireles, Gabriela Sofía, La trayectoria de Tomás Murphy Porro: cambios y permanencias en las élites económicas del virreinato en el México independiente, Tesis de Doctorado, México, Universidad Nacional Autónoma de México, 2014.

Ibarra, Antonio, Mercado e institución: corporaciones comerciales, redes de negocios y crisis colonial. Guadalajara en el siglo XVIII, México, Universidad Autónoma de México, Bonilla Artigas Editores, 2017.

Lerdo de Tejada, Miguel, Comercio exterior de México desde la conquista hasta hoy, México, Banco Nacional de Comercio Exterior, 1967.

Malamud, Carlos, «Sin marina, sin tesoro y casi sin soldados». La financiación de la reconquista de América, 1810-1826, Santiago, Centro de Estudios Bicentenario, 2007.

Marichal, Carlos, «El comercio neutral y los consorcios extranjeros en Veracruz, 1805-1808», en Yuste López, Carmen y Matilde Souto Mantecón (comps.), El comercio exterior de México (1713-1850), México, Veracruz, Instituto de Investigaciones José María Luis Mora, Instituto de Investigaciones Históricas, Universidad Nacional Autónoma de México, Universidad Veracruzana, 2000, pp. 163-192.

Mazzeo, Cristina, El comercio libre en el Perú. Las estrategías de un comerciante criollo: José Antonio de Lavalle y Cortés, 1777-1815, Lima, Pontificia Universidad Católica del Perú, Fondo Editorial, 1994.

Muñoz Pérez, José, «La supresión de la Casa de la Contratación de Cádiz, 1790-1793», en Cádiz en su historia, II Jornadas de Historia de Cádiz, Cádiz, Caja de Ahorros de Cádiz, 1983, pp. 91 123.

Ortiz de la Tabla Ducasse, Javier, El comercio exterior de Veracruz, 1778-1821: crisis de dependencia, Sevilla, Escuela de Estudios Hispanoamericanos, 1978.

Ortiz Escamilla, Juan, El teatro de la guerra. Veracruz, 1750-1825, Castelló de la Plana, Universitat Jaume I, 2008.

Ruiz García, Vicente, Las naves de las Cortes (1808-1812). El último servicio de la Marina de la Ilustración, Madrid, Sílex, 2013. 
Schlez, Mariano Martín, Los circuitos comerciales tardo-coloniales: El caso de un comerciante monopolista: Diego de Agüero (1770-1820), Buenos Aires, Universidad de Buenos Aires, 2014.

Smith, Roberts S., «Shipping in the Port of Veracruz, 1790-1821», Hispanic American History Review, n. ${ }^{\circ} 23$, Durham, 1943, pp. 5-20.

Souto Mantecón, Matilde, Mar abierto. La política y el comercio del Consulado de Veracruz en el ocaso del sistema imperial, México, El Colegio de México, Centro de Estudios Históricos, Instituto José María Luis Mora, 2001.

Tandrón, Humberto, El comercio de Nueva España y la controversia sobre la libertad de comercio, 1796-1821, México, Instituto Mexicano de Comercio Exterior, 1976.

Trujillo Bolio, Mario, El Péndulo marítimo-mercantil en el Atlántico novohispano (1798-1825). Comercio libre, circuitos de intercambio, exportación e importación, México, Cádiz, CIESAS, Universidad de Cádiz, 2009, pp. 45-72. 